\title{
Intra- and inter-species mobilisation of non-conjugative plasmids in staphylococci
}

\author{
E. E. UDO, H. LOVE and W. B. GRUBB*
}

School of Biomedical Sciences, Curtin University of Technology, GPO Box U 1987, Perth 6001, Western Australia

\begin{abstract}
Summary. The ability of Staphylococcus aureus conjugative plasmids to mobilise nonconjugative resistance plasmids from clinical isolates of $S$. aureus and $S$. epidermidis was studied. Plasmids which could not be transferred by transduction or mixed-culture transfer were transferred from phage-typable and non-typable $S$. aureus and from $S$. epidermidis. Plasmids encoding single resistance determinants were transferred by mobilisation whereas multiple-resistance plasmids were transferred as co-integrates between the conjugative and non-conjugative plasmids. This study demonstrates that mobilisation is a useful tool for the transfer and study of staphylococcal plasmids and illustrates how antibiotic resistance could be transferred between staphylococci in vivo.
\end{abstract}

\section{Introduction}

Plasmids are important carriers of resistance genes and have been reported in nearly all species of medically important bacteria. Plasmid-determined antimicrobial resistance in Staphylococcus aureus can be transferred between strains in vitro by transduction, phage-mediated conjugation, or mixed-culture transfer (MCT) and conjugation. ${ }^{1}$ Increasing numbers of recent isolates of $S$. aureus are untypable with the international set of typing phages. ${ }^{2-7}$ Consequently, phage-dependent methods of plasmid transfer cannot be used to transfer plasmids from the non-typable isolates because these methods require that the donor and recipient be lysed or lysogenised by appropriate bacteriophages. $^{8}$

Coagulase-negative staphylococci (CNS) are involved increasingly in infections, especially in the elderly and in immunocompromised patients. ${ }^{9-15}$ They are often multi-resistant to antimicrobial agents and

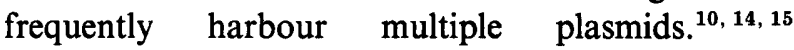
However, plasmids in CNS have not been studied extensively because of the lack of a suitable method for plasmid transfer.

Conjugation, unlike transduction and MCT, appears to be independent of bacteriophages ${ }^{1}$ and, therefore, does not depend on phage susceptibility. The majority of conjugative plasmids reported in $S$. aureus and $S$. epidermidis can mobilise and transfer non-conjugative plasmids. ${ }^{16-24}$ However, the ability of conjugative plasmids to mobilise non-conjugative plasmids has not been exploited as a tool for isolating and studying plasmids from staphylococcal isolates.

In this study, the ability of the conjugative plasmid
pWBG637 ${ }^{20}$ to transfer non-conjugative resistance plasmids from $S$. aureus and $S$. epidermidis was investigated. The study was motivated by previous findings that the conjugative plasmids pWBG636 and pWBG642 ${ }^{25}$ could transfer from $S$. aureus to $S$. epidermidis and Streptococcus faecalis and back to $S$. aureus. $^{26}$ The results presented here indicate that conjugative plasmids are a useful tool for transferring plasmids in staphylococci in vitro and add further support to the premise that they are important in the transmission of antibiotic resistance in vivo. ${ }^{26}$

\section{Materials and methods}

\section{Bacterial strains}

The bacterial isolates used in this study are listed in table I. Because plasmid pWBG637 has no selective markers, derivatives of it labelled with transposons were used. These were: pWBG636, a 39-2-kb plasmid labelled with the gentamicin-resistance transposon Tn3851 and pWBG642, a 39.9-kb plasmid labelled with the erythromycin-resistance transposon $\operatorname{Tn} 551 .{ }^{25}$ Another conjugative plasmid pWBG653 of $44 \mathrm{~kb}$ and encoding resistance to gentamicin, kanamycin and neomycin ${ }^{25}$ was also used. The recipients were plasmid-free strains; strain WBG541 was resistant to fusidic acid and rifampicin ${ }^{27}$ and strain WBG4515 was resistant to streptomycin and novobiocin. ${ }^{19}$ Isolate WBG7407 was provided by Dr B. Cookson, Central Public Health Laboratory, Colindale Avenue, London.

\section{Media}

Brain Heart Infusion Agar (BHIA), Brain Heart Infusion Broth, Trypticase Soy Broth and Mueller 
Hinton Agar were purchased from Gibco Diagnostics (Madison, WI, USA).

\section{Bacteriophage typing}

This was performed at the State Health Laboratory Service of Western Australia with phages of the International Phage Typing Set.

\section{Susceptibility testing}

Susceptibility to antimicrobial agents was tested by the disk diffusion and replica plating methods described previously. ${ }^{27,28}$

\section{Loss of resistance at $43.5^{\circ} \mathrm{C}$}

Tests for this were performed as described previously. ${ }^{22}$

\section{Isolation and analysis of plasmid DNA}

Plasmids were isolated by the cetyltrimethyl-ammonium bromide method. ${ }^{29}$ Agarose gel electrophoresis (AGE) and mol.-wt determination of plasmid DNA were performed on horizontal gels incorporating agarose (Sigma) $0.5 \% \mathrm{w} / \mathrm{v}$ as described previously. ${ }^{19}$ Restriction endonuclease digestion of plasmids was performed according to the manufacturer's instructions and the fragments were separated on agarose $0.8 \% \mathrm{w} / \mathrm{v}$ gels. Phage $\lambda$ DNA (Pharmacia, Uppsala, Sweden) digested with HindIII or HindIII and EcoRI (Toyobo, Co. Ltd, Osaka, Japan) were used as size standards.

\section{Conjugation}

Conjugation experiments were performed in TSB in the presence of polyethylene glycol (PEG) $40 \% \mathrm{w} / \mathrm{v}$ as described previously. ${ }^{122}$ Mobilisation experiments were performed by first transferring one of the conjugative plasmids to the strain to be tested. The resulting transconjugants were then used as donors in a further conjugation experiment with strain WBG541. Transconjugants were selected on BHIA containing $(\mathrm{mg} / \mathrm{L})$ fusidic acid $(\mathrm{Fa}), 10$ and rifampicin (Rf), 2.5, and one of the following (see table II): streptomycin (Sm), 100; kanamycin $(\mathrm{Km}), 75$; gentamicin $(\mathrm{Gm}), 8$; erythromycin (Em), 5; tetracycline (Tc), 5; chloramphenicol $(\mathrm{Cm}), 10$; trimethoprim $(\mathrm{Tp}), 2.5$; propamidine isethionate $(\mathrm{Pi}), 10$; ethidium bromide $(\mathrm{Eb})$, 120 ; or cadmium (Cd), $2 \times 10^{-2} \mathrm{M}$. Transconjugants were screened for the presence of plasmids by AGE.

\section{Results}

Mobilisation of non-conjugative plasmids from $S$. aureus isolates

A total of $20 \mathrm{~S}$. aureus isolates was studied for transfer of resistance plasmids by mobilisation with the conjugative plasmids pWBG636 and pWBG642. The isolates were resistant to a range of antimicrobial agents and contained at least two plasmids/cell. The resistance and plasmid profiles of representative isolates are shown in table I. They were mostly untypable at 100RTD with phages of the International Typing Set. Only isolates WBG4761, WBG4762, WBG4918, WBG4920, WBG4856 and WBG7407 were susceptible to the International Set of Typing phages.

None of the isolates, except WBG7407, transferred resistance determinants by conjugation before receiving either of the conjugative plasmids, indicating that they did not contain conjugative plasmids. However, resistance was transferred from the isolates after either of the conjugative plasmids pWBG636 or pWBG642 was introduced and the resultant strains were tested for conjugation with the recipient strain, WBG541.

The results of the mobilisation experiments (table II) demonstrated transfer of plasmids ranging from small 3.2-4.4-kb plasmids, encoding single resistances to $\mathrm{Tc}, \mathrm{Sm}$ or $\mathrm{Cm}$, and $5 \cdot 2-\mathrm{kb}$ plasmids, encoding resistance to $\mathrm{Cm}$ and $\mathrm{Sm}$, to plasmids of $15 \cdot 0-38.0 \mathrm{~kb}$ encoding resistance to multiple antimicrobials.

Plasmid analysis performed on the transconjugants revealed that single resistance plasmids encoding $\mathrm{Tc}$, $\mathrm{Sm}$ or $\mathrm{Cm}$ resistance were mobilised either with or without co-transfer of the conjugative plasmid. In approximately one third of the transconjugants, only the single resistance plasmid was transferred while the remainder carried both the single resistance plasmid and the conjugative plasmid.

Both plasmids were maintained separately and no evidence of recombination between the single resistance and the conjugative plasmid was apparent. In contrast, the multi-resistance plasmids were either transferred alone or as recombinants with the conjugative plasmids. This is illustrated with the results obtained when plasmids pWBG659 and pWBG700, both encoding resistance to $\mathrm{Pc}, \mathrm{Cd}$ and arsenate (Asa), were transferred from WBG1004 and WBG4761 respectively with pWBG636 (table II). Two types of transconjugants were obtained with both isolates. One type had plasmids encoding resistance to $\mathrm{Pc}, \mathrm{Cd}$, and Asa which gave $E c o$ RI restriction fragments identical with those of plasmids pWBG659 and pWBG700 from isolates WBG1004 and WBG4761 respectively (data not shown). The other type of transconjugants also contained a single plasmid (e.g. pWBG635 and pWBG686 from isolates WBG1004 and WBG4761 respectively, table II) and were resistant to $\mathrm{Pc}, \mathrm{Cd}$, Asa, $\mathrm{Gm}$ and $\mathrm{Km}$. In curing experiments on this type of transconjugant, resistance to all five antimicrobials was lost concomitantly with the plasmids. EcoRI restriction enzyme analysis (fig. 1) indicated that plasmids pWBG635 and pWBG686 were recombinants between pWBG659 and pWBG636, and pWBG700 and pWBG636, respectively, and were not formed as a result of transposition of the Tn 3851 of pWBG636 to either pWBG659 or pWBG700.

Two 4.4-kb plasmids, one encoding resistance to $\mathrm{Sm}$ 
Table I. Resistance and plasmid profiles of representative staphylococcal isolates

\begin{tabular}{lll}
\hline \multicolumn{1}{c}{$\begin{array}{c}\text { Isolates } \\
\text { nos }\end{array}$} & \multicolumn{1}{c}{ Resistance profile } & \multicolumn{1}{c}{$\begin{array}{c}\text { Plasmid } \\
\text { sizes }(\mathrm{kb})\end{array}$} \\
\hline S. aureus & & \\
WBG1004 & Pc, Cd, Asa, Sm & $38 \cdot 8,4 \cdot 4$ \\
WBG1006 & Pc, Cd, Asa, Sm, Tc & $36 \cdot 8,4 \cdot 4$ \\
WBG4761 & Pc, Cd, Asa, Sm, Cm, Tc, Mn & $36 \cdot 3,5 \cdot 2$ \\
WBG4762 & Pc, Cd, Sm, Cm, Tc, Mn & $20 \cdot 8,5 \cdot 2,4 \cdot 4$ \\
WBG4856 & Pc, Cd, Tc, Tp, Su, Eb & $34 \cdot 5,4 \cdot 4,2 \cdot 8,1 \cdot 9$ \\
WBG4918 & Pc, Cd, Tc, Sm, Hg, Pma & $23 \cdot 8,4 \cdot 4,3 \cdot 8$ \\
WBG4920 & Pc, Cd, Sm, Cm, Tc, Eb, Su & $20 \cdot 8,5 \cdot 2,4 \cdot 4$ \\
WBG4922 & Pc, Cd, Asa, Eb, Sm, Tc, Su & $28 \cdot 4,18 \cdot 2,8 \cdot 8,4 \cdot 4,3 \cdot 0$ \\
WBG4928 & Pc, Cd, Hg, Pma, Tc & $22 \cdot 6,4 \cdot 4$ \\
WBG4940 & Pc, Cd, Sm, Tc, Cm, Su & $30 \cdot 4,10 \cdot 7,5 \cdot 3,4 \cdot 4,3 \cdot 5$ \\
WBG4945 & Pc, Cd, Hg, Pma, Cm & $24 \cdot 0,4 \cdot 4,3 \cdot 5$ \\
WBG4948 & Pc, Cd, Tc, Cm & $28 \cdot 5,4 \cdot 4,3 \cdot 5$ \\
WBG7407 & Mu, Pc, Cd, Tc & $20 \cdot 2,4 \cdot 4$ \\
S. epidermidis & Mc, Asa, Em, Tc, Tp, Su, Eb, Pi & NS \\
WBG7193 & Mc, Pc, Gm, Km, Nm, Sm, Tc, Pi & NS \\
WBG7195 & Pc, Cd, Hg, Asa, Pma, Pi, Su & NS \\
WBG7196 & Pc, Cd, Asa, Eb, Pi, Cm, Gm, Km, Nm, Tp & NS \\
WBG7200 & Mc, Pc, Asa, Km, Em, Tc, Tp, & NS \\
WBG7216 & Su, Hg, Pma, Eb, Pi. & \\
& & \\
\hline
\end{tabular}

Asa, arsenate; $\mathrm{Cd}$, cadmium; $\mathrm{Cm}$, chloramphenicol; $\mathrm{Eb}$, ethidium bromide; $\mathrm{Em}$, erythromycin; $\mathrm{Gm}$, gentamicin; $\mathrm{Hg}$, mercury; $\mathrm{Km}$, kanamycin; $\mathrm{Mc}$, methicillin; $\mathrm{Mn}$, minocycline; Mu, mupirocin; Nm, neomycin; Pc, benzyl penicillin; Pi, propamidine isethionate; Pma, phenyl mercuric acetate; Sm, streptomycin; Su, sulphamethoxazole; Tc, tetracycline; Tp, trimethoprim; NS, not sized.

and the other to Tc, were transferred from isolate WBG1006. Plasmid analysis of WBG1006 revealed that it contained only one $4 \cdot 4-\mathrm{kb}$ band as demonstrated by AGE (fig. 2). When both Tc and Sm resistance was lost from WBG1006 after growth at $43 \cdot 5^{\circ} \mathrm{C}$, the $4 \cdot 4-\mathrm{kb}$ band was also lost, whereas the $4 \cdot 4-$ $\mathrm{kb}$ band was retained when either Tc resistance or $\mathrm{Sm}$ resistance was lost separately (fig. 2). Both plasmids were mobilised by plasmid pWBG636. Of 222 Smresistant transconjugants tested, all were resistant to $\mathrm{Sm}$ only and contained a $4 \cdot 4-\mathrm{kb}$ plasmid band. However, of 222 Tc-resistant transconjugants screened, 221 were resistant to Tc and only one was resistant to Tc and $\mathrm{Sm}$. Both types of Tc-resistant transconjugants contained a $4 \cdot 4-\mathrm{kb}$ plasmid. These results indicate that WBG1006 contained two 4.4-kb plasmids, one encoding $\mathrm{Tc}$ resistance and the other $\mathrm{Sm}$ resistance. Two 4.4-kb plasmids, one encoding Tc resistance and the other $\mathrm{Sm}$ resistance were also transferred separately from isolate WBG4918 (table II).

\section{Analysis of isolate WBG7407}

Isolate WBG7407 was resistant to mupirocin $(\mathrm{Mu})$, $\mathrm{Pc}, \mathrm{Tc}$ and $\mathrm{Cd}$ and contained a 4.4-kb Tc-resistance plasmid, a plasmid of about $20 \mathrm{~kb}$ encoding resistance to $\mathrm{Pc}$ and $\mathrm{Cd}$, and a conjugative $\mathrm{Mu}$-resistance determinant. ${ }^{30}$ When WBG7407 was examined in conjugation experiments with WBG541, only $\mathrm{Mu}$ resistance was transferred and none of $222 \mathrm{Mu}$ resistant transconjugants screened co-transferred resistance to $\mathrm{Tc}, \mathrm{Pc}$ or $\mathrm{Cd}$, indicating that the Tc- resistance and the $\mathrm{Pc}$ - and $\mathrm{Cd}$ - resistance plasmids were not mobilised by the conjugative Mu-resistance determinant. However, when pWBG636 was transferred to WBG7407 it mobilised both these plasmids (table II). The Tc-resistance plasmid was mobilised as a separate plasmid whereas the Pc- and Cd-resistance plasmid was transferred recombined with pWBG636.

\section{Mobilisation of plasmid pWBG632 by pWBG653}

It has been reported previously that the Tc-resistance plasmid pWBG632 present in isolate WBG1024 was not mobilised by the conjugative plasmid pWBG637 $7^{31}$ although pWBG637 mobilises pWBG3, a Tc-resistance plasmid ${ }^{20}$ and has mobilised other Tc-resistance plasmids in this study (table II). Plasmid pWBG632 was studied further to determine whether it could be mobilised by another conjugative plasmid, pWBG653. Plasmid pWBG653 was transferred to strain WBG4856 (carrying pWBG632) and a resultant transconjugant was examined for conjugation with WBG541. Tc resistance was transferred to WBG541 and the transconjugants contained pWBG632 alone or both pWBG632 and pWBG653 (table II).

\section{Mobilisation of non-conjugative plasmids from $S$. epidermidis}

The $S$. epidermidis isolates were resistant to a wide range of antimicrobial agents (table I) and harboured many plasmid bands (not shown). The sizes of these plasmids could not be determined in the parental 
Table II. Mobilisation of plasmids in staphylococci

\begin{tabular}{|c|c|c|c|c|}
\hline $\begin{array}{l}\text { Mobilising } \\
\text { plasmid }\end{array}$ & $\begin{array}{l}\text { Donor } \\
\text { strain* }\end{array}$ & $\begin{array}{l}\text { Selective } \\
\text { markers }\end{array}$ & $\begin{array}{c}\text { Transferred } \\
\text { determinants }\end{array}$ & $\begin{array}{c}\text { Plasmid } \\
\text { and sizes }(\mathbf{k b})\end{array}$ \\
\hline & S. aureus & & & \\
\hline \multirow[t]{39}{*}{ pWBG636 } & WBG1004 & FaRfSm & $\mathrm{Sm}$ & $4 \cdot 4$ \\
\hline & WBG1004 & FaRfSm & $\mathrm{Sm}, \mathrm{Gm}$ & $4 \cdot 4,39 \cdot 2$ (pWBG636) \\
\hline & WBG1004 & FaRfCd & Pc, Asa, Cd & 38.8 (pWBG659) \\
\hline & WBG1004 & FaRfCd & Pc, Asa, Cd, Gm & 78.4 (pWBG635) \\
\hline & WBG1004 & FaRfGm & & $39 \cdot 2$ (pWBG636) \\
\hline & WBG1004 & FaRfGm & $\mathrm{Gm}, \mathrm{Sm}$ & $4 \cdot 4,39.2$ (pWBG636) \\
\hline & WBG1004 & FaRfGm & Gm, Pc, Asa, Cd & 78.4 (pWBG635) \\
\hline & WBG1006 & FaRfSm & & 4.4 (pWBG623) \\
\hline & WBG1006 & FaRfSm & $\mathrm{Sm}, \mathrm{Gm}$ & $4 \cdot 4,39 \cdot 2$ (pWBG636) \\
\hline & WBG1006 & FaRfTc & $\mathrm{Tc}$ & 4.4 (pWBG622) \\
\hline & WBG1006 & FaRfTc & $\mathrm{Tc}, \mathrm{Sm}$ & $4 \cdot 4,4 \cdot 4$ \\
\hline & WBG1006 & FaRfTc & $\mathrm{Tc}, \mathrm{Gm}$ & $4 \cdot 4,39 \cdot 2$ (pWBG636) \\
\hline & WBG1006 & FaRfCd & Nil & Nil \\
\hline & WBG1006 & FaRfGm & $\mathrm{Gm}$ & 39.2 (pWBG636) \\
\hline & WBG1006 & FaRfGm & $\mathrm{Gm}, \mathrm{Tc}$ & $4 \cdot 4,39 \cdot 2$ (pWBG636) \\
\hline & WBG1006 & FaRfGm & $\mathrm{Gm}, \mathrm{Sm}$ & $4 \cdot 4,39 \cdot 2$ (pWBG636) \\
\hline & WBG4761 & FaRfSm & $\mathrm{Sm}, \mathrm{Cm}$ & $5 \cdot 2$ \\
\hline & WBG4761 & FaRfSm & $\mathrm{Sm}, \mathrm{Cm}, \mathrm{Gm}$ & $5 \cdot 2,39 \cdot 2$ (pWBG636) \\
\hline & WBG4761 & $\mathrm{FaRfCm}$ & $\mathrm{Sm}, \mathrm{Cm}$ & 5.2 \\
\hline & WBG4761 & FaRfCd & Pc, Asa, Cd & 39.8 (pWBG700) \\
\hline & WBG4761 & FaRfCd & Gm, Pc, Asa, Cd & 79.1 (pWBG686) \\
\hline & WBG4761 & FaRfTc & Nil & Nil \\
\hline & WBG4762 & FaRfSm & $\mathrm{Sm}, \mathrm{Cm}$ & $5 \cdot 2$ \\
\hline & WBG4762 & FaRfSm & $\mathrm{Gm}, \mathrm{Sm}, \mathrm{Cm}$ & $5 \cdot 2,39 \cdot 2$ (pWBG636) \\
\hline & WBG4762 & FaRfCm & $\mathrm{Sm}, \mathrm{Cm}$ & $5 \cdot 2$ \\
\hline & WBG4762 & FaRCm & $\mathrm{Gm}, \mathrm{Sm}, \mathrm{Cm}$ & 5.2. $39 \cdot 2$ (pWBG636) \\
\hline & WBG4918 & FaRfTc & Tc & $4 \cdot 4$ \\
\hline & WBG4918 & FaRfSm & $\mathrm{Sm}$ & $4 \cdot 4$ \\
\hline & WBG4918 & FaRfGm & $\mathrm{Gm}$ & $39 \cdot 2$ (pWBG636) \\
\hline & WBG4918 & FaRfGm & $\mathrm{Gm}, \mathrm{Sm}$ & $4 \cdot 4,39.2$ (pWBG636) \\
\hline & WBG4918 & FaRfGm & $\mathrm{Gm}, \mathrm{Tc}$ & $4 \cdot 4,39 \cdot 2$ (pWBG636) \\
\hline & WBG4920 & FaRfSm & $\mathrm{Sm}, \mathrm{Cm}$ & $5 \cdot 2$ \\
\hline & WBG4920 & FaRfSm & $\mathrm{Gm}, \mathrm{Sm}, \mathrm{Cm}$ & $5 \cdot 2,39 \cdot 2$ (pWBG636) \\
\hline & WBG4920 & FaRfCm & $\mathrm{Sm}, \mathrm{Cm}$ & $5 \cdot 2$ \\
\hline & WBG4920 & FaRfCm & $\mathrm{Gm}, \mathrm{Sm}, \mathrm{Cm}$ & $5 \cdot 2,39 \cdot 2$ (pWBG636) \\
\hline & WBG4920 & FaRfTc & Tc & $4 \cdot 4$ \\
\hline & WBG4920 & FaRfTc & $\mathrm{Gm}, \mathrm{Tc}$ & $4 \cdot 4,39 \cdot 2$ (pWBG636) \\
\hline & WBG 4920 & FaRfCd & Cd & 20.8 \\
\hline & WBG4920 & FaRfCd & $\mathrm{Gm}, \mathrm{Cd}$ & NS \\
\hline \multirow[t]{10}{*}{ pWBG642 } & WBG4940 & FaRfCm & $\mathrm{Cm}$ & 3.5 \\
\hline & WBG4940 & FaRfCm & $\mathrm{Cm}, \mathrm{Em}$ & $3.5,39.9$ (pWBG642) \\
\hline & WBG4940 & FaRfSm & Nil & Nil \\
\hline & WBG4940 & FaRfEm & Em & 39.9 (pWBG642) \\
\hline & WBG4940 & FaRfEm & $\mathrm{Em}, \mathrm{Cm}$ & $3.5,39.9$ (pWBG642) \\
\hline & WBG4948 & $\mathrm{FaRfCm}$ & $\mathrm{Cm}$ & $3 \cdot 5$ \\
\hline & WBG4948 & FaRfCm & $\mathrm{Em}, \mathrm{Cm}$ & $3.5,39.9$ (pWBG642) \\
\hline & WBG4948 & FaRfCd & $\mathrm{Nil}$ & Nil \\
\hline & WBG4948 & FaRfEm & Em & 39.9 (pWBG642) \\
\hline & WBG4948 & FaRfEm & $\mathrm{Em}, \mathrm{Cm}$ & $3.5,39.9$ (pWBG642) \\
\hline \multirow[t]{3}{*}{ pWBG636 } & WBG7407 & FaRfTc & Tc & $4 \cdot 4$ \\
\hline & WBG7407 & FaRfTc & Tc & $4.4,39.2$ (pWBG636) \\
\hline & WBG7407 & FaRfCd & $\mathrm{Gm}, \mathrm{Pc}, \mathrm{Cd}$ & NS \\
\hline \multirow[t]{2}{*}{ pWBG653 } & WBG4856 & FaRfTc & Tc & $4 \cdot 4$ \\
\hline & $\begin{array}{l}\text { WBG } 4856 \\
\text { S. epidermidis }\end{array}$ & FaRfTc & Tc & $4 \cdot 4,44 \cdot 0$ (pWBG653) \\
\hline \multirow{9}{*}{$\begin{array}{l}\text { pWBG636 } \\
\text { pWBG642 }\end{array}$} & WBG7193 & FaRfEm & Em, Eb, Pi & 39.0 \\
\hline & WBG7195 & FaRfGm & $\mathrm{Gm}, \mathrm{Km}$ & 39.9 (pWBG684) \\
\hline & WBG7195 & FaRfKm & $\mathrm{Gm}, \mathrm{Km}$ & 39.9 (pWBG684) \\
\hline & WBG7195 & FaRfTc & Tc & $4 \cdot 4$ \\
\hline & WBG7195 & FaRfTc & $\mathrm{Em}, \mathrm{Tc}$ & $4.4,39.9$ (pWBG642) \\
\hline & WBG7196 & FaRfEb & $\mathrm{Pc}, \mathrm{Pi}, \mathrm{Eb}$ & $17 \cdot 0$ \\
\hline & WBG7196 & FaRfEb & Em, Pc, Pi, Eb & $17.0,39.9$ (pWBG642) \\
\hline & WBG7196 & FaRfEm & $\mathrm{Em}$ & 39.9 (pWBG642) \\
\hline & WBG7196 & FaRfEm & $\mathrm{Em}, \mathrm{Pc}, \mathrm{Pi}, \mathrm{Eb}$ & $17.0,39.9$ (pWBG642) \\
\hline \multirow[t]{6}{*}{ pWBG636 } & WBG7200 & FaRfCm & $\mathrm{Cm}$ & 4.5 \\
\hline & WBG7200 & $\mathrm{FaRfCm}$ & $\mathrm{Gm}, \mathrm{Cm}$ & $4 \cdot 5,39 \cdot 2$ (pWBG636) \\
\hline & WBG7200 & FaRfEm & $\mathrm{Em}, \mathrm{Tp}$ & 42.0 \\
\hline & WBG7216 & FaRfTc & Tc, Pc, Km & 28.0 \\
\hline & WBG7216 & FaRfKm & $\mathrm{Tc}, \mathrm{Pc}, \mathrm{Km}$ & 28.0 \\
\hline & WBG7216 & FaRfPi & $\mathrm{Tp}, \mathrm{Su}, \mathrm{Pi}$ & $17 \cdot 1$ \\
\hline
\end{tabular}

See footnote to table $\mathbf{I} ; \mathrm{Fa}$, fusidic acid; $\mathbf{R f}$, rifampicin.

* Clinical isolate which has received a conjugative plasmid. 


\section{5}

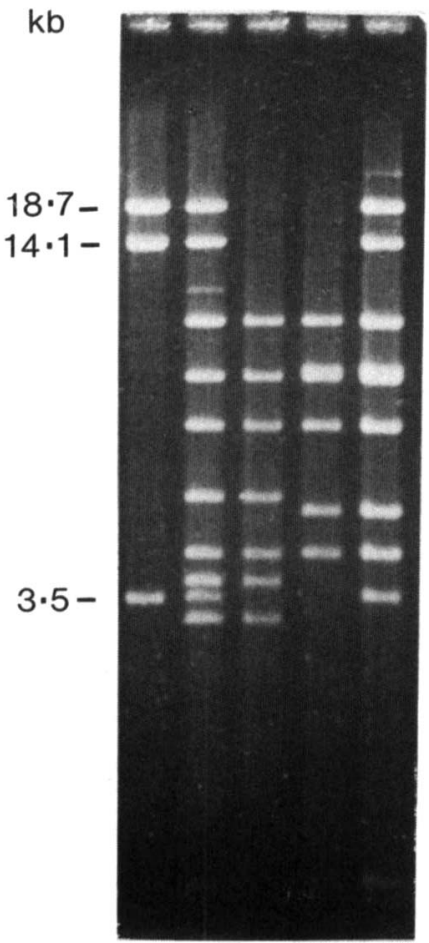

Fig. 1. EcoRI digests of plasmids pWBG636, pWBG635, pWBG659, pWBG700 and pWBG686: lane 1, pWBG636 $\mathrm{Gm}^{\mathrm{r}}$, tra ${ }^{+}$, the 1.6and $1.4-\mathrm{kb}$ fragments are not visible in this gel; 2, pWBG635 $\mathrm{Gm}^{\mathrm{r}} \mathrm{Pc}^{\mathrm{r}} \mathrm{Cd}^{\mathrm{r}} \mathrm{Asa}^{\mathrm{r}} ;$ 3, pWBG659 $\mathrm{Pc}^{\mathrm{r}} \mathrm{Cd}^{\mathrm{r}} \mathrm{Asa}^{\mathrm{r}} ; \quad$ 4, pWBG700 $\mathrm{Pc}^{\mathrm{r}} \mathrm{Cd}^{\mathrm{r}} \mathrm{Asa}^{\mathrm{r}} ;$ 5, pWBG686 $\mathrm{Gm}^{\mathrm{r}} \mathrm{Pc}^{\mathrm{r}} \mathrm{Cd}^{\mathrm{r}} \mathrm{Asa}{ }^{\mathrm{r}}$.

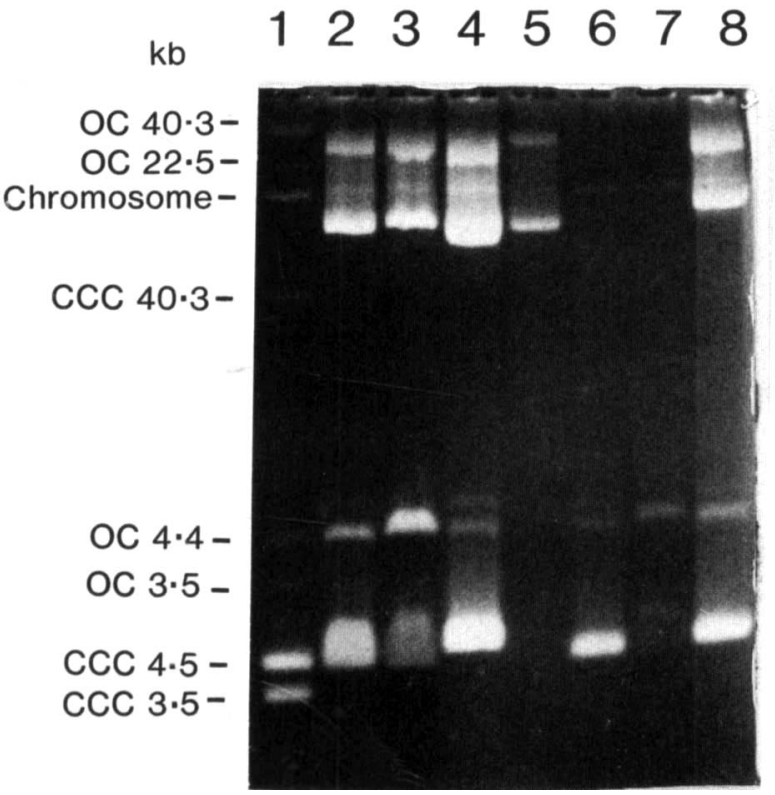

Fig. 2. Plasmids of isolate WBG1006 and its derivatives: lane 1, WBG4483 carrying mol.- wt markers; 2, WBG1006; 3, WBG1006 cured of $\mathrm{Tc}^{r} ; 4$, WBG1006 cured of $\mathrm{Sm}^{\mathrm{r}} ; 5$, WBG1006 cured of $\mathrm{Sm}^{t}$ and $\mathrm{Tc}^{\mathrm{r}} ; 6$, a $\mathrm{Tc}^{\mathrm{r}}$ transconjugant carrying a $4 \cdot 4-\mathrm{kb}$ plasmid, pWBG622; 7, a $\mathrm{Sm}^{\mathrm{r}}$ transconjugant carrying a $4 \cdot 4-\mathrm{kb}$ plasmid, pWBG623 (the OC form is prominent in this gel); 8, a transconjugant carrying the $\mathrm{Tc}^{\mathrm{r}}$ plasmid pWBG622 and the conjugative plasmid pWBG636.

isolates because it was difficult to ascertain which of the bands represented covalently-closed circular or open-circular forms. However, the plasmids were sized

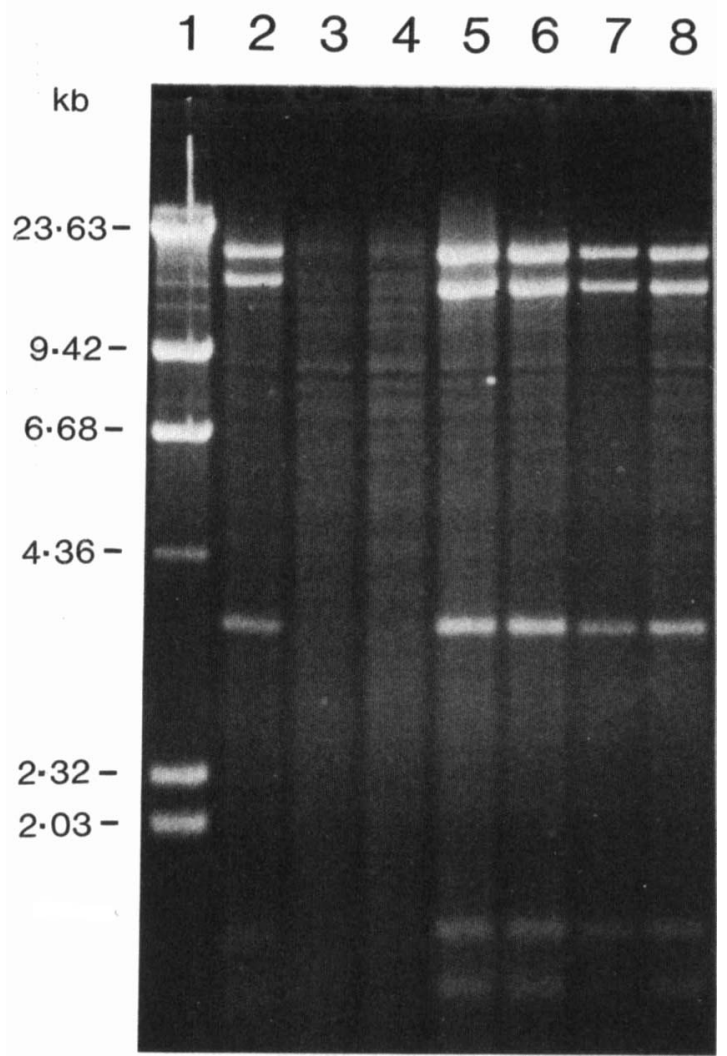

Fig. 3. EcoRI digest of plasmids pWBG642 and pWBG684. Lane 1, HindIII digest of phage $\lambda$ DNA (the faint bands are partial digests); 2, pWBG642 $\mathrm{Em}^{\mathrm{r}}$, $\operatorname{tra}^{+}$; 5-8, pWBG684 $\mathrm{Gm}^{\mathrm{r}} \mathrm{Km}^{\mathrm{r}}$, tra $^{+}$.

and their resistance phenotypes determined once they were transferred to strain WBG541.

Small $4 \cdot 4-4 \cdot 5-\mathrm{kb}$ plasmids encoding resistance to Tc or $\mathrm{Cm}$ and $17-42-\mathrm{kb}$ plasmids encoding multiresistance were transferred from S. epidermidis (table II). Linked resistance to $\mathrm{Tc}, \mathrm{Pc}$ and $\mathrm{Km}$ were transferred from WBG7216 and were borne on a single $28 \cdot 0-\mathrm{kb}$ plasmid. Resistance to the nucleic-acid-binding compounds ${ }^{32} \mathrm{Pi}$ and ethidium bromide $(\mathrm{Eb})$ were transferred from WBG7196 and WBG7193 and were found to be encoded on $17 \cdot 0-\mathrm{kb}$ and $39 \cdot 0-\mathrm{kb}$ plasmids. The latter plasmid also carried a Pc-resistance gene.

\section{Transposon displacement}

The S. epidermidis isolate WBG7195 was resistant to methicillin, $\mathrm{Gm}, \mathrm{Km}$, neomycin, $\mathrm{Sm}, \mathrm{Tc}$ and $\mathrm{Pi}$. When the conjugative plasmid pWBG642 (Em resistance) was used to transfer plasmids from WBG7195, resistance to $\mathrm{Gm}$ and $\mathrm{Km}$ was transferred and the transconjugants examined contained plasmids of the same size as pWBG642 but encoded resistance to $\mathrm{Gm}$ and $\mathrm{Km}$. One of these plasmids was designated pWBG684. Proof that plasmid pWBG684 encodes resistance to $\mathrm{Gm}$ and $\mathrm{Km}$ was obtained when one of the transconjugants carrying pWBG684 was examined by conjugation with strain WBG4515. Gm and $\mathrm{Km}$ resistance was transferred to strain WBG4515 and the transconjugants were shown to contain pWBG684. This result also indicates that pWBG684 is a conjugative plasmid. EcoRI restriction enzyme analysis 
indicated that pWBG684 had EcoRI restriction patterns similar to those of pWBG642 (fig. 3) although it encoded resistance to $\mathrm{Gm}$ and $\mathrm{Km}$ instead of $\mathrm{Em}$. It would appear that the $\mathrm{Gm}$ and $\mathrm{Km}$ resistance determinants had displaced the Em-resistance transposon Tn551 in plasmid pWB642 and occupied its site. This phenomenon is described as 'transposon displacement'.

\section{Discussion}

The increasing incidence of untypable $S$. aureus isolates has not only limited the use of phage typing for studying the epidemiology of $S$. aureus but it has meant that neither transduction nor MCT, which require both donor and recipient cells to be susceptible to the transferring phage, ${ }^{8}$ can be used for transferring plasmids from non-typable $S$. aureus isolates.

We investigated the use of plasmid mobilisation by conjugative plasmids as an alternative to phagemediated methods for transferring plasmids from staphylococci. This has been made possible by the discovery of conjugative plasmids that have no resistance phenotypes. ${ }^{20,22}$ One of these plasmids has been labelled with different resistance transposons ${ }^{25}$ and this has enabled them to be used with isolates with a range of resistance profiles. The results presented have demonstrated that mobilisation by conjugative plasmids can be an effective tool for transferring nonconjugative plasmids from typable and non-typable $S$. aureus and $S$. epidermidis, an organism for which phage-mediated transfer systems are not well characterised.

Two separate 4.4-kb plasmids, one encoding Tc resistance and the other Sm resistance, were transferred from isolates WBG1006 and WBG4918. On one occasion both Tc- and Sm-resistance plasmids were co-transferred on Tc selection but this did not appear to result from recombination between the two replicons as the transconjugant had the same $4 \cdot 4-\mathrm{kb}$ band as WBG1006. A recombinant plasmid would have been expected to be larger than that in WBG1006. The transfer of two separate $4 \cdot 4-\mathrm{kb}$ plasmids, one encoding Tc resistance and the other Sm resistance, confirms earlier reports that determinants for $\mathrm{Tc}$ and $\mathrm{Sm}$ resistance co-transduced from other $S$. aureus isolates existed as separate replicons. ${ }^{33,34}$

The results indicate that, whereas the small 3.2-5.2$\mathrm{kb}$ plasmids were mobilised and were transferred with or without the conjugative plasmid, the large plasmids appeared to be transferred via co-integrate formation. Plasmids pWBG635 and pWBG686 appear to be cointegrates of pWBG659 and pWBG636, and pWBG700 and pWBG636, respectively (fig. 1), which have not resolved in the transconjugants.

Mobilisation was more successful with $S$. aureus than with $S$. epidermidis plasmids. It is possible that some of the plasmids in the S. epidermidis isolates that appeared not to be mobilised were cryptic and, therefore, no positive selection pressure was available to obtain transconjugants, even if they were mobilisable.

The transfer of $\mathrm{Gm}$ and $\mathrm{Km}$ resistance from $S$. epidermidis isolate WBG7195 yielded plasmid pWBG684 which was conjugative and similar in size $(39.9 \mathrm{~kb}$, table II) to, and had the same EcoRI restriction endonuclease pattern as, plasmid pWBG642 (fig. 3). However, plasmid pWBG684 differed from pWBG642 in encoding resistance to $\mathrm{Gm}$ and $\mathrm{Km}$ and not to Em. It appears that pWBG684 was pWBG642 in which the Gm-Km-resistance determinants had displaced Tn551 and occupied its site. Consequently, this phenomenon has been referred to as 'transposon displacement'. The Gm-Km-resistance determinant of WBG7195 is probably a transposon similar to Tn4031, a Gm-resistance transposon reported in S. epidermidis. ${ }^{35}$ The fate of Tn 551 after the displacement is uncertain. It was not transposed to the chromosome of WBG541 as none of the Gm-Kmresistant transconjugants was resistant to Em. It would appear that little, if any, of Tn551 remained on the plasmid as the acquisition of the determinants for $\mathrm{Gm}$ and $\mathrm{Km}$ resistance did not result in any detectable increase in size of the plasmid. Further analysis is required to understand this new phenomenon. However, it represents another method whereby conjugative plasmids are able to acquire and disseminate resistance genes.

As not all the plasmids detected in the isolates were mobilised by pWBG636 and pWBG642, it is possible that some of these plasmids could be mobilised by other conjugative plasmids. Support for this view is three-fold: (i) the Tc-resistance plasmid pWBG632 was not mobilised by pWBG637 but was mobilised by pWBG653; (ii) pWBG636 was able to mobilise a Tcresistance plasmid from isolate WBG7407 which was not mobilised by the conjugative $\mathrm{Mu}$-resistance determinant of WBG7407; and (iii) the report that the conjugative plasmid pG01 could not mobilise plasmids pT181 and pE194, ${ }^{24}$ whereas plasmids pE194 and pWBG3, a plasmid similar to pT181, were mobilised by pWBG637. ${ }^{20}$ Therefore, the use of different sets of conjugative plasmids should increase the number of plasmids transferred in staphylococci.

Mobilisation of non-conjugative plasmids in staphylococci may be similar to the situation in Escherichia coli, in which it has been observed that some plasmids can be efficiently mobilised by one conjugative plasmid and not by another. An example is plasmid RSF100 which is mobilised efficiently by IncP plasmids, but poorly by $I n c I$ and $I n c W$ plasmids and not at all by Inc $\mathrm{F}$ plasmids. ${ }^{36}$ Although the conjugative plasmids in $S$. aureus belong to at least three incompatibility groups, ${ }^{25,}{ }^{37}$ it is not yet known whether incompatibility plays any role in the mobilisation of plasmids in S. aureus.

Although these studies have all been performed in vitro, the demonstration that conjugation can occur in $v^{i v o^{38-40}}$ suggests that the mobilisation described here 
could also occur in vivo. If this is true, these results should increase our understanding of how antimicrobial resistance may be disseminated in clinical staphylococcal isolates.

\section{References}

1. Townsend DE, Bolton S, Ashdown N, Grubb WB. Transfer of plasmid-borne aminoglycoside-resistance determinants in staphylococci. J Med Microbiol 1985; 20 : 169-185.

2. Jette LP. Phage types of Staphylococcus aureus received at the Quebec Public Health Laboratory from 1976 to $1983 . J$ Clin Microbiol 1986; 23: 180-181.

3. Lyon BR, May JW, Skurray RA. Analysis of plasmids in nosocomial strains of multiple-antibiotic-resistant Staphylococcus aureus. Antimicrob Agents Chemother 1983; 23: 817-826.

4. Gillespie MT, May JW, Skurray RA. Antibiotic resistance in Staphylococcus aureus isolated at an Australian hospital between 1946-1982. J Med Microbiol 1985; 19: 137-147.

5. Marples RR, Richardson JF, De Saxe MJ. Bacteriological characters of strains of Staphylococcus aureus submitted to a reference laboratory related to methicillin resistance. $J$ Hyg 1986; 96: 217-223.

6. Duckworth GJ, Lothian JLE, Williams JD. Methicillin-resistant Staphylococcus aureus: report of an outbreak in a London teaching hospital. J Hosp Infect 1988; 11 : 1-15.

7. Schaefler S, Jones D, Perry W et al. Emergence of gentamicinand methicillin-resistant Staphylococcus aureus strains in New York City hospitals. J Clin Microbiol 1981; 13: 754-759.

8. Lacey RW. Evidence for two mechanisms of plasmid transfer in mixed cultures of Staphylococcus aureus. J Gen Microbiol $1980 ; 119: 423-435$.

9. Christensen GD, Bisno AL, Parisi JT, McLaughlin B, Hester MG, Luther RW. Nosocomial septicaemia due to multiply antibiotic-resistant Staphylococcus epidermidis. Ann Intern Med 1982; 96: 1-10.

10. Parisi JT, Hecht DW. Plasmid profiles in epidemiologic studies of infections by Staphylococcus epidermidis. $J$ Infect Dis $1980 ; 141$ : 637-643.

11. Parisi JT. Coagulase-negative staphylococci and the epidemiological typing of Staphylococcus epidermidis. Microbiol Rev 1985; 49: 126-139.

12. Gemmel CG. Coagulase-negative staphylococci. J Med Microbiol 1986; 22: 285-295.

13. Karchmer AW, Archer GL, Dismukes WE. Staphylococcus epidermidis causing prosthetic valve endocarditis: microbiologic and clinical observations as guides to therapy. Ann Intern Med 1983; 98: 447-455.

14. Archer GL, Vishniavsky N, Stiver HG. Plasmid pattern analysis of Staphylococcus epidermidis isolates from patients with prosthetic valve endocarditis. Infect Immun 1982; 35: 628-632.

15. Archer GL, Dietrick DR, Johnston JL. Molecular epidemiology of transmissible gentamicin resistance among coagulasenegative staphylococci in a cardiac surgery unit. $J$ Infect Dis 1985 ; 151 : 243-251.

16. McDonnell RW, Sweeney HM, Cohen S. Conjugational transfer of gentamicin resistance plasmids intra- and interspecifically in Staphylococcus aureus and Staphylococcus epidermidis. Antimicrob Agents Chemother 1983; 23: $151-160$.

17. Archer GL, Johnston JL. Self-transmissible plasmids in staphylococci that encode resistance to aminoglycosides. Antimicrob Agents Chemother 1983; 24: 70-77.

18. Forbes BA, Schaberg DR. Transfer of resistance plasmids from Staphylococcus epidermidis to Staphylococcus aureus: evidence for conjugative exchange of resistance. $J$ Bacteriol 1983 ; 153: 627-634.

19. Townsend DE, Bolton S, Ashdown N, Grubb WB. Transfer of plasmid-borne aminoglycoside-resistance determinants in staphylococci. J Med Microbiol 1985; 20 : 169-185.
We are grateful to $\mathrm{Dr}$ B. Cookson for providing the Mu- resistant isolate WBG7407 and the State Health Laboratory Service of Western Australia for phage typing. This work was funded by grants to WBG from the National Health and Medical Research Council and Markalinga Management (Western Diagnostic Services).

20. Udo E, Townsend DE, Grubb WB. A conjugative staphylococcal plasmid with no resistance phenotype. FEMS Microbiol Letts 1987; 40: 279-283.

21. Evans J, Dyke KGH. Characterization of the conjugation system associated with the Staphylococcus aureus plasmid pJE1. J Gen Microbiol 1988; 134: 1-8.

22. Udo EE, Grubb WB. Excision of a conjugative plasmid from the staphylococcal chromosome. J Med Microbiol 1990; 33: 227-234.

23. Goering RV, Asch DK. Plasmid mobilisation effected by a conjugal aminoglycoside-resistance plasmid in Staphylococcus aureus. Zentralbl Bakteriol Parasitenkd Infektionskr Hyg Abt 1 1985; Suppl 14: 563-565.

24. Projan SJ, Archer GL. Mobilization of the relaxable Staphylococcus aureus plasmid $\mathrm{pC} 221$ by the conjugative plasmid pG01 involves three pC221 loci. J Bacteriol 1989; 171: 1841-1845.

25. Udo EE, Grubb WB. A new class of conjugative plasmid in Staphylococcus aureus. J Med Microbiol 1990; 31 : 207-212.

26. Udo EE, Grubb WB. Conjugal transfer of plasmid pWBG637 from Staphylococcus aureus to Staphylococcus epidermidis and Streptococcus faecalis. FEMS Microbiol Letts 1990; 72: $183-188$.

27. Townsend DE, Grubb WB, Ashdown N. Gentamicin resistance in methicillin-resistant Staphylococcus aureus. Pathology 1983; 15: 169-174.

28. Annear DI, Grubb WB. Linked and unstable resistance to kanamycin and penicillin, and diffusible pigment production, in an isolate of Staphylococcus aureus. $\mathrm{J} \mathrm{Med}$ Microbiol 1972; 5: 109-111.

29. Townsend DE, Ashdown N, Bolton S, Grubb WB. The use of cetyltrimethylammonium bromide for the rapid isolation from Staphylococcus aureus of relaxable plasmid DNA for in vitro manipulation. Letts Appl Microbiol 1985; 1 : 87-94.

30. Rahman M, Noble WC, Cookson B. Transmissible mupirocin resistance in Staphylococcus aureus. Epidemiol Infect 1989; 102: 261-270.

31. Udo EE, Grubb WB. Transfer of resistance determinants from a multi-resistant Staphylococcus aureus isolate. $\mathrm{J} \mathrm{Med}$ Microbiol 1991; 35: 72-79.

32. Emslie KR, Townsend DE, Grubb WB. A resistance determinant to nucleic acid-binding compounds in methicillinresistant Staphylococcus aureus. J Med Microbiol 1985; 20: 139-145.

33. Grubb WB, O'Reilly RJ. Joint transduction of separate extrachromosomal drug resistance determinants in Staphylococcus aureus E169. Biochem Biophys Res Commun 1971, 42: 377-383.

34. Grubb WB, O'Reilly RJ, May JW. Segregation of cotransduced streptomycin and tetracycline resistance in Staphylococcus aureus. Genet Res $1972 ; 20: 43-50$.

35. Thomas WD, Archer GL. Mobility of gentamicin resistance genes from staphylococci isolated in the United States: identification of $\mathrm{Tn} 4031$, a gentamicin resistance transposon from Staphylococcus epidermidis. Antimicrob Agents Chemother 1989; 33: 1335-1341.

36. Willetts N, Wilkins B. Processing of plasmid DNA during bacterial conjugation. Microbiol Rev 1984; 48: 24-41.

37. Udo EE, Grubb WB.A new incompatibility group plasmid in Staphylococcus aureus. FEMS Microbiol Letts 1991; 78 33-36.

38. Townsend DE, den Hollander L, Bolton S, Grubb WB. Clinical isolates of staphylococci conjugate on contact with dry absorbent surfaces. Med J Aust 1986; 144: 166.

39. Naidoo J, Noble WC. Transfer of gentamicin resistance between strains of Staphylococcus aureus on skin. J Gen Microbiol 1978; 107 : 391-393.

40. Naidoo J, Noble WC. Transfer of gentamicin resistance between staphylococci on skin. J Hyg 1981 ; 86: 183-187. 